Check for updates

Cite this: Chem. Sci., 2019, 10, 7183

¿ All publication charges for this article have been paid for by the Royal Society of Chemistry

\section{Catalytic $\mathrm{Au}(\mathrm{I}) / \mathrm{Au}(\mathrm{III})$ arylation with the hemilabile MeDalphos ligand: unusual selectivity for electron- rich iodoarenes and efficient application to indoles $\dagger$}

\author{
Jessica Rodriguez, (iD a Abdallah Zeineddine, ${ }^{a}$ E. Daiann Sosa Carrizo, (DD ${ }^{b}$ \\ Karinne Miqueu, (D) ${ }^{\text {b }}$ Nathalie Saffon-Merceron, ${ }^{\mathrm{C}}$ Abderrahmane Amgoune ${ }^{\text {*a }}$ \\ and Didier Bourissou (D)*a
}

\begin{abstract}
The ability of the hemilabile $(P, N)$ MeDalphos ligand to trigger oxidative addition of iodoarenes to gold has been thoroughly studied. Competition experiments and Hammett correlations substantiate a clear preference of gold for electron-enriched substrates both in stoichiometric oxidative addition reactions and in catalytic $\mathrm{C}-\mathrm{C}$ cross-coupling with 1,3,5-trimethoxybenzene. This feature markedly contrasts with the higher reactivity of electron-deprived substrates typically encountered with palladium. Based on DFT calculations and detailed analysis of the key transition states (using NBO, CDA and ETS-NOCV methods in particular), the different behavior of the two metals is proposed to result from inverse electron flow between the substrate and metal. Indeed, oxidative addition of iodobenzene is associated with a charge transfer from the substrate to the metal at the transition state for gold, but opposite for palladium. The higher electrophilicity of the gold center favors electron-rich substrates while important back-donation from palladium favors electron-poor substrates. Facile oxidative addition of iodoarenes combined with the propensity of gold(III) complexes to readily react with electron-rich (hetero)arenes prompted us to apply the (MeDalphos)AuCl complex in the catalytic arylation of indoles, a challenging but very important transformation. The gold complex proved to be very efficient, general and robust. It displays complete regioselectivity for $\mathrm{C} 3$ arylation, it tolerates a variety of functional groups at both the iodoarene and indole partners $\left(\mathrm{NO}_{2}, \mathrm{CO}_{2} \mathrm{Me}, \mathrm{Br}, \mathrm{OTf}, \mathrm{Bpin}, \mathrm{OMe} \ldots\right)$ and it proceeds under mild conditions $\left(75^{\circ} \mathrm{C}, 2 \mathrm{~h}\right)$.
\end{abstract}

Received 19th April 2019

Accepted 13th June 2019

DOI: $10.1039 / c 9 s c 01954 \mathrm{e}$

rsc.li/chemical-science for transformations in which gold displays reactivity and/or selectivity complementary to the other transition metals. The main challenge in this field is certainly to generate aryl gold(III) species ready to participate in cross-coupling. To do so, several strategies have progressively emerged, as schematically illustrated in Fig. 1A. The first and main approach consists in using aryl-silanes, aryl-boronic acids or even simple arenes with external oxidants, typically $\mathrm{F}^{+}$sources or I(III) compounds (route a). This methodology has been used successfully in a number of catalytic oxidative coupling reactions, in particular for the arylation of (hetero)arenes ${ }^{3}$ and for the oxy (and amino) arylation of alkenes. ${ }^{4}$ Starting from 2013, aryl diazonium salts (and diaryl iodonium salts) have been developed as alternative coupling partners (route b). Using this approach, the key aryl gold(III) species are most commonly generated under light activation, with or without a photosensitizer (thermal and base-activation are also possible), which circumvents the use of strong oxidants. The efficiency and generality of this method have already been substantiated in a number of catalytic $\mathrm{C}-\mathrm{C}$ and $\mathrm{C}-\mathrm{E}$ ( $\mathrm{E}=\mathrm{P}, \mathrm{S}$, halogen) coupling reactions, in particular thanks to dual photoredox and gold catalysis. ${ }^{5}$ Very recently, a third 


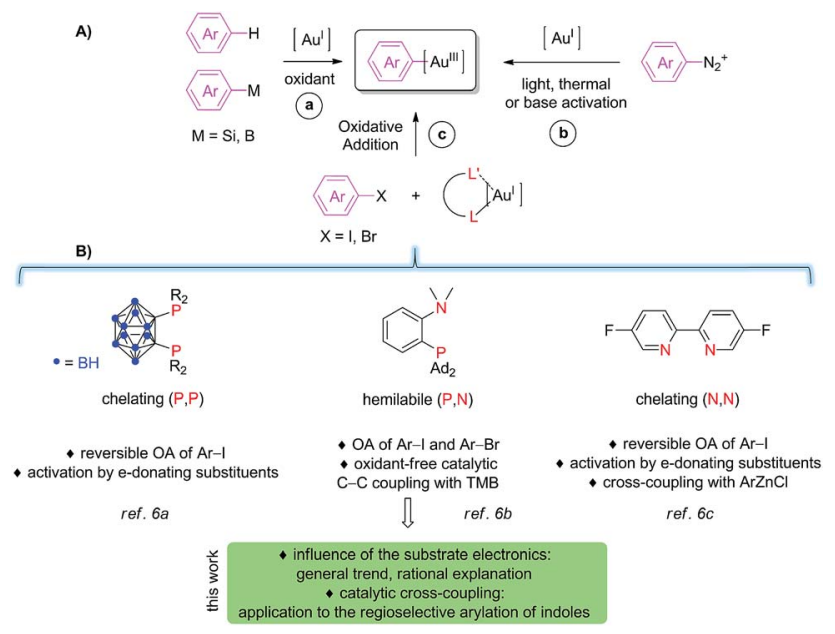

Fig. 1 (A) Schematic representation of the different means to access aryl gold(III) species to participate in cross-coupling reactions; (B) bidentate ligands shown to promote oxidative addition of aryl halides to gold.

approach relying on purposely-designed ligands has been introduced (route c). Chelating and hemilabile ligands were shown to enable oxidant-free coupling reactions with aryl halide electrophiles (Fig. 1B)..$^{6-8}$

Our group first discovered that $o$-carboranyl diphosphines emulate oxidative addition to gold. The bending induced by the chelating $(\mathrm{P}, \mathrm{P})$ ligand activates and preorganizes the metal fragment so that oxidative addition of iodoarenes ${ }^{6 a}$ as well as strained carbocycles ${ }^{9}$ proceeds readily. In the course of these investigations, we noticed an unusual substituent effect. ${ }^{10}$ Indeed, iodoarenes featuring electron-donating (EDG) parasubstituents were found to react with the $(\mathrm{P}, \mathrm{P})$ gold $(\mathrm{I})$ complex significantly faster than those bearing electron-withdrawing groups (EWG), in marked contrast with that classically observed with other transition metals. ${ }^{11}$ We then extended the ligand-based approach to MeDalphos, a hemilable ligand. ${ }^{6 b, 12}$ With the $(\mathrm{P}, \mathrm{N})$ gold complex, oxidative addition proved to be even more favored. The scope of iodoarenes was further extended and bromoarenes could be activated as well. In addition, we showed that the ensuing $(\mathrm{P}, \mathrm{N})$ aryl gold(III) complexes do engage in $\mathrm{C}-\mathrm{C}$ coupling with 1,3,5-trimethoxybenzene (TMB) used as a model electron-rich arene. The cross-coupling reaction between iodoarenes and TMB was amenable to catalysis, using $5 \mathrm{~mol} \%$ of the $(\mathrm{P}, \mathrm{N})$ gold complex. The $(\mathrm{P}, \mathrm{N})$ aryl gold(III) species were then reported by Maynard and Spokoyny to readily undergo stoichiometric aryl-S coupling with unprotected peptides and proteins, providing a very efficient and chemoselective mean for cysteine bioconjugation. ${ }^{13}$ Last but not least, a bipyridine ligand was shown very recently by McGrady, Bower and Russell to also promote oxidative addition to gold. ${ }^{6 c}$ With this chelating $(\mathrm{N}, \mathrm{N})$ ligand, iodoarenes are reversibly activated and again, electron-rich substrates were found to react unusually faster than electron-poor ones. The resulting $(\mathrm{N}, \mathrm{N})$ aryl gold(III) complex undergoes transmetallation and $\mathrm{C}-\mathrm{C}$ reductive elimination upon reaction with an aryl zinc reagent, providing evidence for all the elementary steps of a gold-promoted Negishi-type coupling.

From all these recent reports, it is clear that ligand design offers new perspectives in gold chemistry, in particular for $\mathrm{Au}(\mathrm{I}) /$ $\mathrm{Au}$ (III) catalysis, but the field is still in its infancy. Indeed, we know very little about oxidative addition to gold and catalytic applications with aryl halides as substrates have to be developed beyond the proof-of-concept arylation reaction of TMB. In the present study, we aimed to gain more insight into the seemingly specific trend of gold towards substituted aryl halides. We tried in particular to address the following questions: Does the $(\mathrm{P}, \mathrm{N})$ gold complex also display a preference for electron-rich substrates? Does the substituent influence observed for the oxidative addition step transpose to the catalytic crosscoupling? What is the reason for the difference between gold and the other transition metals, palladium in particular? In addition, we sought to illustrate the synthetic interest of the $(\mathrm{P}, \mathrm{N})$ gold complex in catalysis and thoroughly investigated the direct catalytic arylation of indoles. The results obtained along these two lines are reported hereafter.

\section{Results and discussion}

\section{Relative reactivities of substituted iodoarenes in the oxidative addition to the $(P, N)$ gold complex}

As we pointed out for the (P,P) gold complex, ${ }^{6 a}$ the influence of the iodoarene electronics on the rate of oxidative addition to gold is unique and intriguing. As mentioned above, a similar tendency was recently observed by McGrady, Bower, Russell et al. with a $2,2^{\prime}$-bipyridyl, $(\mathrm{N}, \mathrm{N})$ chelated gold complex. ${ }^{6 c}$ This raises the question of the generality of this trend and if so, of the reason for such a specific behavior of gold. We thus examined the relative reactivities of a series of parasubstituted iodoarenes with the $(\mathrm{P}, \mathrm{N})$ gold complex. To start with, the scope of the reaction was further extended (Scheme 1). Electron-poor substrates featuring a $p-\mathrm{CF}_{3}$ as well as $p$-CN and $p$-COMe substituents - two potentially coordinating groups - were found to undergo oxidative addition to gold within the time of mixing. With the electron-rich $p-\mathrm{NMe}_{2}$ substituted iodobenzene, a complex mixture of gold complexes was obtained, which might be due to competitive $\mathrm{N}$ coordination to gold and/or redox processes. ${ }^{14}$ In contrast, $p$ $\mathrm{Br}$ iodobenzene reacted smoothly with complete selectivity for C-I oxidative addition.

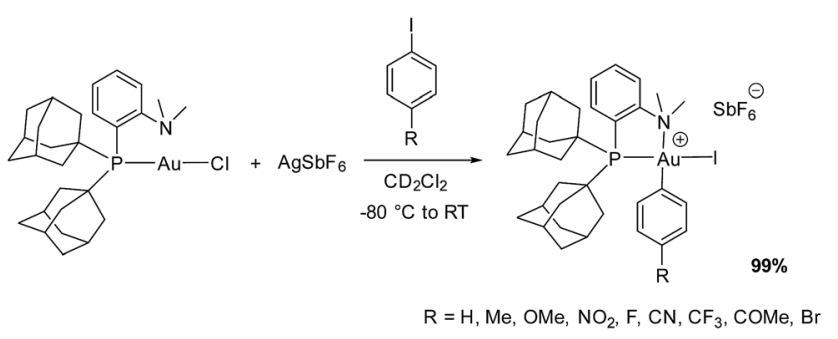

Scheme 1 Oxidative addition of a series of para-substituted iodoarenes to the $(P, N)$ gold complex. 
The rate of Ar-I oxidative addition to the $(\mathrm{P}, \mathrm{N})$ gold complex is much faster than with the $(\mathrm{P}, \mathrm{P})$ ligand, preventing a direct comparison of the substrates based on their reaction times (all reactions are complete by the time the medium reaches room temperature). We thus resorted to competition experiments and first performed a few test reactions to determine whether the electron-rich/electron-poor character of the substrate matters or not. Two competition experiments were carried out between $p$ $(\mathrm{MeO}) \mathrm{C}_{6} \mathrm{H}_{4} \mathrm{I}$ as electron-rich substrate and $p$-(MeCO) $\mathrm{C}_{6} \mathrm{H}_{4} \mathrm{I}$ or $p$ $\left(\mathrm{F}_{3} \mathrm{C}\right) \mathrm{C}_{6} \mathrm{H}_{4} \mathrm{I}$ as electron-poor substrate (Scheme 2). ${ }^{14}$ In each case, equimolar amounts of the two substituted iodoarenes were mixed and added in 10-fold molar excess to a solution of the $(\mathrm{P}, \mathrm{N})$ gold complex to ensure that the concentration of the two halides remains approximately constant over the reaction (Scheme 2). The ratio of the resulting gold(III) complexes was determined by ${ }^{31} \mathrm{P}$ NMR spectroscopy. In both cases, the major product formed corresponds to the gold(III) complex P1 ensuing from oxidative addition of the electron-rich $p$-OMe iodobenzene (in $64 / 36$ ratio with $p$-COMe and $87 / 13$ ratio with $p-\mathrm{CF}_{3}$ iodobenzene). To confirm this trend, another competition reaction was performed with $p-\left(\mathrm{F}_{3} \mathrm{C}\right) \mathrm{C}_{6} \mathrm{H}_{4} \mathrm{I}$ and $p-\mathrm{MeC}_{6} \mathrm{H}_{4} \mathrm{I}$. Here also, the major product corresponds to the oxidative addition of the iodobenzene bearing the electron-donating group (in 84/16 ratio).

These encouraging results prompted us to run a Hammett type analysis. To this end, iodobenzene was reacted with the $(\mathrm{P}, \mathrm{N})$ gold complex in competition with several para-substituted iodoarenes ( $p$-OMe, $p$-Me, $p$ - $\mathrm{Br}$ and $p-\mathrm{CF}_{3}$ ) following the same protocol (1:1 mixture of the two iodoarenes, 10-fold molar excess with respect to $\mathrm{Au}$ ). Under these pseudo-first-order conditions, the relative rate constants for the oxidative addition can be derived from the ratio of the gold(III) products (P1 vs. P2). The Hammett correlation against $\sigma_{\mathrm{P}}$ values ${ }^{15}$ (Fig. 2) reveals a good linear correlation $\left(R^{2}=0.93\right)$. The negative slope $(\rho=$ $-1.09)$ confirms the preference of the gold complex to react with electron-rich iodoarenes. This contrasts with the general trend of group 10 metals to react faster with electron-poor substrates,${ }^{11}$ as reflected in the positive $\rho$ values reported for palladium. The magnitude of the $\rho$ value for gold is in the lower range of those reported for palladium (1.5-2.3) ${ }^{16}$ The negative sign of the $\rho$ value found for the gold complex indicates a buildup of positive charge on the aromatic ring upon oxidative

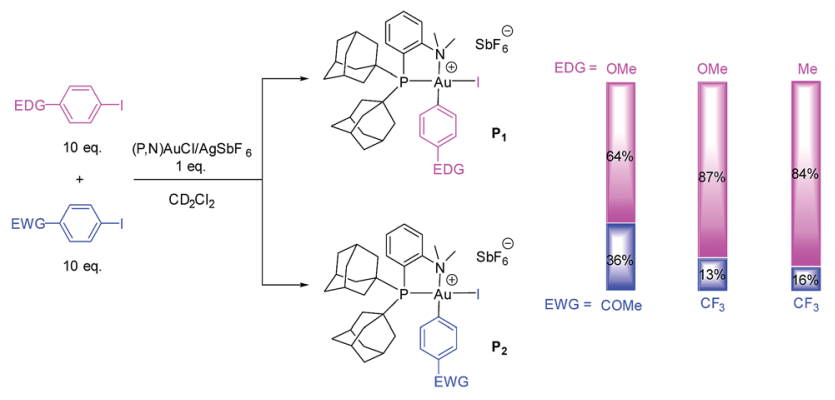

Scheme 2 Test competition reactions between EDG and EWG parasubstituted iodoarenes in the oxidative addition to the $(P, N)$ gold complex.

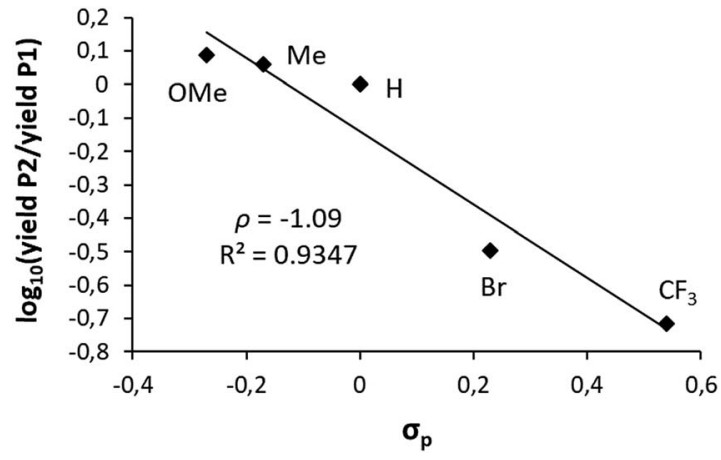

Fig. 2 Hammett correlation for the oxidative addition of different para-substituted iodoarenes to the $(P, N)$ gold complex.

addition of the iodoarene and thus suggests an electrophilic behavior of gold.

The $(\mathrm{P}, \mathrm{N})$ gold complex thus displays the same reverse electronic trend towards iodoarenes than the $(\mathrm{P}, \mathrm{P})$ and $(\mathrm{N}, \mathrm{N})$ chelated complexes, suggesting it is a general feature of gold complexes to react faster with electron-rich substrates. This prompted us to further examine the oxidative addition path computationally to try to decipher possible underlying factors.

\section{DFT analysis of the oxidative addition path to gold, and comparison with palladium}

Our previous DFT studies have substantiated the key role of the chelating $(\mathrm{P}, \mathrm{N})$ ligand. $^{6 b}$ It lowers the activation barrier of oxidative addition and stabilizes the ensuing aryl gold(III) species thanks to coordination of the nitrogen atom to gold. The weakly coordinating $\mathrm{SbF}_{6}{ }^{-}$counter-anion was also shown to play no major role. Its displacement by iodobenzene proceeds with a very low activation barrier and the ratedetermining step is the oxidative addition to gold. As a result, the gold preference for electron-rich iodoarenes is unlikely to originate from the initial displacement of $\mathrm{SbF}_{6}{ }^{-}$at gold, but rather stands in the oxidative addition process itself.

The structure of the associated transition state was thus further analyzed (Fig. 3A). ${ }^{14}$ Charge analysis reveals an electron transfer from iodobenzene to gold (by 0.16 e according to Bader charges computed at the transition state, Atom-In-Molecules calculations), in line with the electrophilic behavior of the gold complex observed experimentally. Consistently, NBO (Natural Bond Orbital) and CDA (Charge Decomposition Analysis) indicate that donor-acceptor interactions from $\mathrm{PhI}$ to $\mathrm{Au}$ largely prevail (Tables S5 and S6†). ${ }^{14}$ Most significant is the donation from an iodine lone pair to the vacant $\sigma^{*}(\mathrm{Au}-\mathrm{P})$ orbital which is associated with a stabilization energy of $c a$ $40 \mathrm{kcal} \mathrm{mol}^{-1}$. The sum of stabilizing energies for $\mathrm{PhI} \rightarrow \mathrm{Au}$ interactions amounts to $c a 72 \mathrm{kcal} \mathrm{mol}^{-1}$ whereas $\mathrm{Au} \rightarrow \mathrm{PhI}$ back-donations sum to only $\sim 13 \mathrm{kcal} \mathrm{mol}^{-1}$. The donation/ back-donation ratio $(\mathrm{d} / \mathrm{b})$ as estimated by CDA is 2.67 . Thus, despite the electron-donation from the nitrogen atom, the gold atom remains highly electrodeficient and the oxidative addition of the $\mathrm{C}_{\mathrm{sp}} 2-\mathrm{I}$ bond is associated with a charge transfer from $\mathrm{PhI}$ to $\mathrm{Au}^{17}{ }^{17}$ Note that recent detailed analyses of gold carbonyl 
(A)

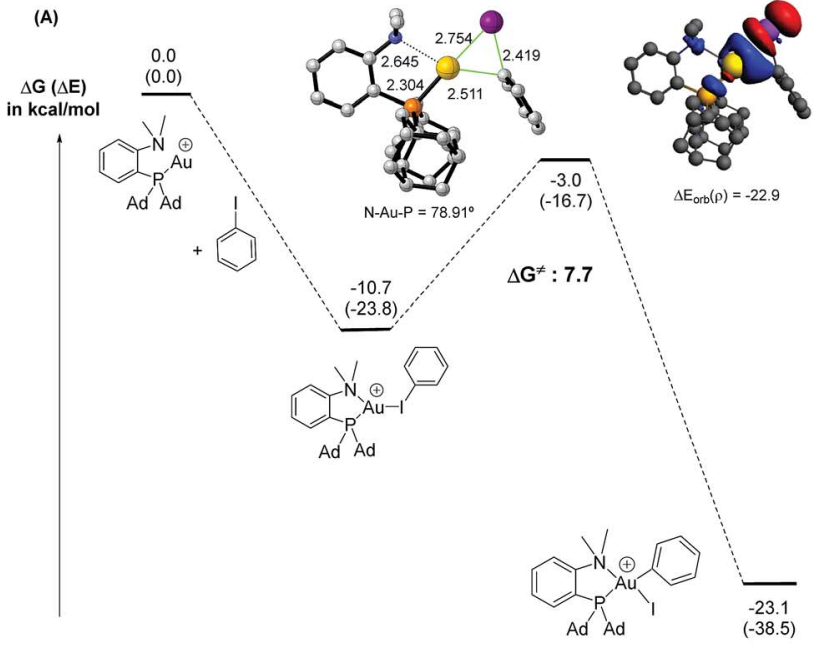

(B)

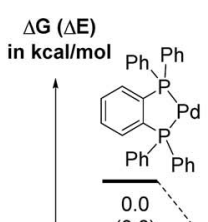
$(0.0)$ (

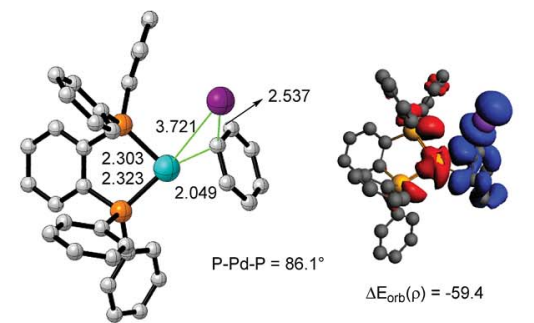

Fig. 3 Reaction profiles computed for the oxidative addition of iodobenzene to the real $(P, N)$ gold complex $(A)$ and to a model $(P, P)$ palladium complex (B). Calculations performed at the B97D(SMD$\mathrm{DCM}) / \mathrm{SDD}+\mathrm{f}(\mathrm{Au}, \mathrm{Pd}), \mathrm{SDD}(\mathrm{I}), 6-31 \mathrm{G} *$ (other atoms) level of theory. Structure of the transition state of oxidative addition (bond lengths in $\AA$, bond angles in ${ }^{\circ}$ ). Contour plot of the NOCV deformation density $\Delta \rho_{\text {orb }}$ and the associated stabilizing energy $\left(\Delta E_{\text {orb }}(\rho)\right.$, in $\left.\mathrm{kcal} \mathrm{mol}^{-1}\right)$ for the predominant orbital interaction between $\mathrm{Phl}$ and the $\mathrm{Au} / \mathrm{Pd}$ metal fragments. The charge flow is red $\rightarrow$ blue $(\Delta \rho<0$ in red and $\Delta \rho>0$ in blue). Analysis performed at ZORA-BP86-D3/TZ2P level of theory. The contour value for density is 0.001 a.u.

complexes have also pointed out the high electrophilicity of cationic gold(I) complexes. Here, strong $\sigma(\mathrm{CO})$ to gold charge transfer results in an uncommon high-energy shift of the CO stretching frequency due to $\mathrm{C} \leftarrow \mathrm{O}$ polarization. ${ }^{\mathbf{1 8}}$

Oxidative addition of iodobenzene to a model chelating diphosphine Pd complex was also theoretically investigated to draw comparison between the two metals (Fig. 3B). In line with previous calculations, ${ }^{19}$ the $\mathrm{C}_{\mathrm{sp}} 2-\mathrm{I}$ bond activation at palladium is very favored thermodynamically and proceeds with a very low activation barrier $\left(\sim 1 \mathrm{kcal} \mathrm{mol}^{-1}\right)$. The structure of the corresponding transition state was analyzed in detail. Of note, the charge transfer is opposite to that found with gold (electron transfer of 0.46 e from Pd to PhI according to the Bader charges). The NBO picture is also quite different from that encountered with the gold complex. The $\mathrm{PhI} \rightarrow \mathrm{Pd}$ and $\mathrm{Pd}$ $\rightarrow$ PhI donor-acceptor interactions are much more balanced. The sum of stabilizing energies are 71 and $30 \mathrm{kcal} \mathrm{mol}^{-1}$, respectively (NBO) and the $\mathrm{d} / \mathrm{b}$ ratio is 0.73 (CDA). This reflects a significantly higher contribution of Pd to PhI back-donation in the oxidative addition process, in line with the observed charge transfer from the metal to the substrate. We surmised that the reverse electron flow in the oxidative addition transition state is responsible for the different behavior of the two metals. Important back-donation from palladium favors electron-deprived substrates whereas the electrophilicity of the gold center favors electron-rich substrates. This difference probably stems from the intrinsic properties of the two metals, as well as from the charge of the reacting metal species (cationic vs. neutral). Chelation and bending of the $\mathrm{L}_{2} \mathrm{Au}^{+}$ fragment has been reported to enhance back-donation from gold $^{20}$ but the cationic and electro-deficient character of the metal remains and makes the difference with neutral $\mathrm{L}_{2} \mathrm{Pd}$ moieties.

To further analyze the different behavior of gold and palladium, the NOCV (Natural Orbital for the Chemical Valence) extension of the EDA (Energy Decomposition Analysis) approach was used and the charge flow in the transition state of oxidative addition was analyzed (Table S7, Fig. S30†). ${ }^{\mathbf{1 4 2 1}}$ For both gold and palladium, the electrostatic term contributes to $49-52 \%$ of the interaction between the metal fragment and substrate, while the orbital term accounts for $40-42 \%$. The primary orbital interaction is associated with substrate to metal donation for gold, but metal to substrate back-donation for palladium. The associated deformation densities $\Delta \rho$ are represented in Fig. 3, substantiating inverse charge flows of the electron density (red $\rightarrow$ blue). The overall charge flow estimated by Hirshfeld partitioning confirms the electron-accepting behavior of gold ( 0.08 e transfer from PhI) but electrondonating behavior of palladium (0.38 e transfer to PhI).

\section{Relative reactivities of iodoarenes in the gold-catalyzed cross- coupling with TMB}

We were then keen to examine if the reverse electronic trend observed with gold in the oxidative addition step may be extrapolated to the catalytic cross-coupling of iodoarenes. For this purpose, competition experiments analogous to those described above have been performed to compare the relative reactivities of para-substituted iodoarenes in the cross-coupling with TMB catalyzed by the $(\mathrm{P}, \mathrm{N})$ gold complex. The reactions were carried out under the previously reported conditions ( $5 \mathrm{~mol} \%$ Au complex, 1.05 eq. $\mathrm{AgSbF}_{6}, 1$ eq. $\mathrm{K}_{3} \mathrm{PO}_{4}, 75^{\circ} \mathrm{C}, 2 \mathrm{~h}$ ), except that we used a 10 -fold excess of the para-substituted iodoarene and iodobenzene with respect to TMB. The ratios of the resulting biaryl products $\left[\mathbf{P}_{1}\right] /\left[\mathbf{P}_{2}\right]$ were determined by GC at complete consumption of TMB and used to build the Hammett correlation shown in Fig. 4. 


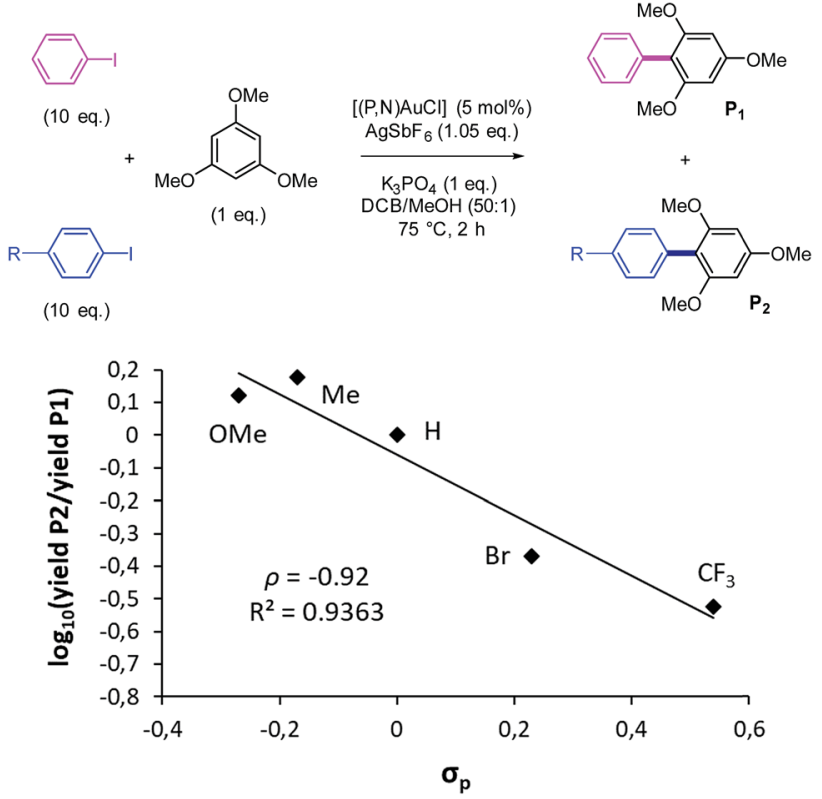

Fig. 4 Competition cross-coupling reaction of para-substituted iodoarenes with TMB and associated Hammett correlation.

As observed for the oxidative addition step, the reactivity of iodoarenes towards cross-coupling with TMB increases with increasing the electron donating ability of the para-substituent (Table S2 $\dagger$ ). ${ }^{14}$ The slope of the Hammett correlation is negative and similar in magnitude to that found for the oxidative addition step ( $\rho$ value $=-1.09$ vs. -0.92$){ }^{22,23}$ Thus, the unusual electronic trend observed in the oxidative addition under stoichiometric conditions is transposed to the cross-coupling reaction under catalytic conditions. The favoured activation and coupling of iodoarenes featuring electron-donating substituents as observed with the $(\mathrm{P}, \mathrm{N})$ gold complex is quite unique. It markedly contrasts with the behavior of group 10 metals and provides an efficient alternative to the goldcatalyzed coupling reactions under oxidative and/or photoredox conditions, for which electron-rich aryl electrophiles are challenging substrates. ${ }^{3-5}$

\section{Synthetic application of gold-catalyzed cross-coupling to the arylation of indoles}

We were then interested in applying our gold-catalyzed arylation methodology to an important and challenging transformation with the aim to assess how gold compare with the other transition metals and eventually complement their performance. In this perspective, we targeted the preparation of aryl-substituted indoles, which are important structural motifs found in many natural products and pharmaceuticals. ${ }^{24}$ The arylation of indoles with transition metal catalysts has garnered tremendous efforts over the last two decades and Pd clearly occupies the forefront position (Scheme 3). ${ }^{25,26}$ The main challenge of the transformation is the control of regioselectivity in the absence of directing groups. Most transition metals tend to intrinsically favour C2 arylation, ${ }^{25,27}$

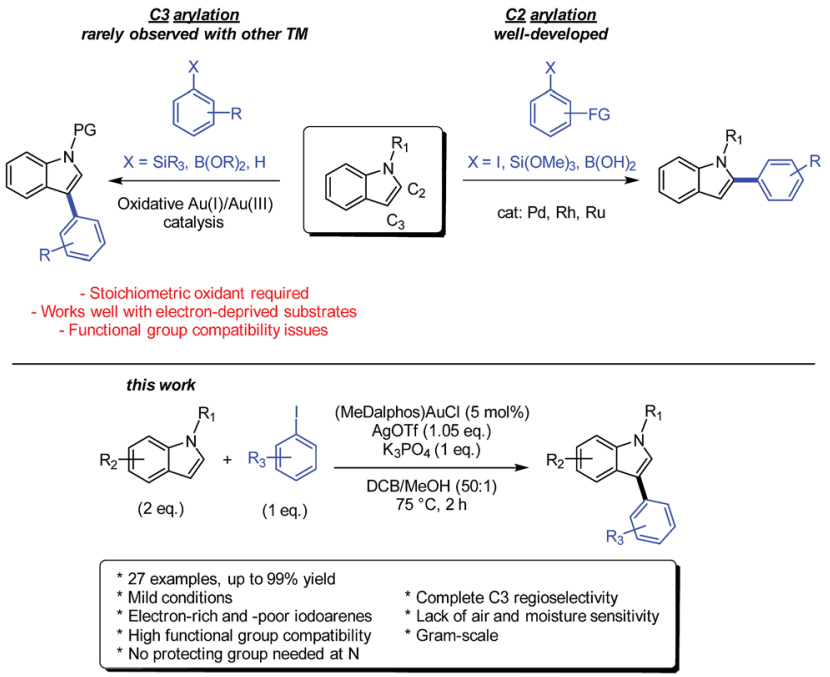

Scheme 3 Transition metal catalyzed methodologies for the regioselective arylation of indoles.

while direct arylations of indoles at the $\mathrm{C} 3$ position remain scant. ${ }^{28,29}$

Over the last few years, gold-catalyzed methodologies have started to be developed for the arylation of indoles. These transformations are based on the oxidative coupling of $\mathrm{N}$ substituted indoles with aryl silanes, ${ }^{30}$ aryl boronates ${ }^{3 f}$ or perfluoro arenes ${ }^{3 d}$ (see ESI and Scheme $\mathrm{S} 1 \dagger$ for a detailed state-ofthe-art). An appealing feature of these gold-catalyzed reactions lies in the mild conditions in which they operate, typically between room temperature and $110^{\circ} \mathrm{C}$, while $\mathrm{Pd}$, $\mathrm{Rh}$ and $\mathrm{Ru}-$ catalyzed reactions generally require prolonged heating at $120{ }^{\circ} \mathrm{C}$ or above. Moreover, gold selectively promotes C3 arylation in the absence of directing groups and is thus very complementary to the other transition metals (Scheme 3). However, the gold-catalyzed arylation of indoles remains relatively limited in scope. Due to compatibility issues associated with the use of a strong oxidant in stoichiometric amount, the indole is generally protected with an electron-withdrawing group at $\mathrm{N}$ (such as $\mathrm{Ts}, \mathrm{Si} \mathrm{Pr}_{3}$ or Piv). Electron-deprived arylating reagents are also usually preferred, the presence of strong electron-donating substituents commonly leading to greater extents of side-reactions. Note that merging gold and photoredox catalysis ${ }^{2}$ offers another way to achieve $\mathrm{Au}(\mathrm{I}) / \mathrm{Au}$ (III) crosscouplings, but attempts to apply this methodology to the arylation of indoles have been unsuccessful so far due to competing azo coupling. ${ }^{\text {.e }}$

The promising preliminary result we obtained upon arylation of $N$-phenyl pyrrole (61\% yield of coupling with $9 / 1$ selectivity in favor of the $\beta$ isomer $)^{6 b}$ prompted us to investigate the $(\mathrm{P}, \mathrm{N})$ gold catalyst for the coupling of indoles and iodoarenes. As reported hereafter, it proved to be very efficient, general and robust, giving access to a variety of C3-arylated indoles with complete regioselectivity within 2 hours at $75^{\circ} \mathrm{C}$.

To start with, the coupling of $N$-methyl indole with iodobenzene was tested under the catalytic conditions used for the arylation of TMB and $N$-phenyl pyrrole (1 eq. of each substrate, 
$5 \mathrm{~mol} \%$ of (P,N)AuCl complex, 1.05 eq. of $\mathrm{AgSbF}_{6}, 1$ eq. of $\mathrm{K}_{3} \mathrm{PO}_{4}, o$-DCB/MeOH $\left.50: 1,75{ }^{\circ} \mathrm{C}, 2 \mathrm{~h}\right) .{ }^{6 b} \mathrm{GC}-\mathrm{MS}$ analysis of the crude mixture revealed the formation of a single regioisomer of phenyl-substituted $\mathrm{N}$-methyl indole but only in trace amount. Fast screening of the reaction conditions enabled significant improvement. Using two equivalents of $\mathrm{N}$-methyl indole and replacing $\mathrm{AgSbF}_{6}$ by AgOTf, the coupling product was obtained in $99 \%$ yield (Scheme 4 ). ${ }^{31}$ The $\mathrm{TfO}^{-}$counter-anion is more coordinating than $\mathrm{SbF}_{6}{ }^{-}$and may stabilize the gold(III) intermediate by the time the indole reacts. ${ }^{1} \mathrm{H}$ NMR spectroscopy indicated the exclusive formation of the $\mathrm{C} 3$-arylated product $1 .^{32}$ This regioselectivity is consistent with the $\mathrm{C}-\mathrm{H}$ activation of the indole at gold proceeding via electrophilic aromatic substitution. ${ }^{33}$

Next, we examined the applicability of these catalytic conditions to the reaction of iodobenzene with different $\mathrm{N}$ substituted indoles (Scheme 4). The reaction works well with $N$ phenyl and $N$-benzyl indoles to afford the corresponding aryl products 2 and 3 in high yields (95 and 82\%, respectively) and with complete C3 regioselectivity. Noticeably, the $\mathrm{N}$-tosyl and $\mathrm{N}$ triisopropylsilyl protected substrates used standardly in goldcatalyzed oxidative arylations of indoles ${ }^{3 d, 30}$ did not work in our conditions (the $N$-Ts indole is inert while the $N$-Si $i \operatorname{Pr}_{3}$ undergoes desilylation). No coupling product was detected either with $\mathrm{N}$-acetyl indole. Indoles not depleted in electron density are needed for the reaction to take place, underpinning the electrophilic mechanism of the indole auration. ${ }^{28 c}$ Selective arylation of unprotected indoles is challenging. It often requires harsh conditions and gives mixtures of regioisomers. It was thus of interest to test our methodology with $\mathrm{N}-\mathrm{H}$ indole. The coupling proceeded with moderate yield (51\%), but gratifyingly the C3-arylated product $\mathbf{4}$ was obtained without by-products stemming from $\mathrm{N}$ or $\mathrm{C} 2$ arylation. This regioselectivity is
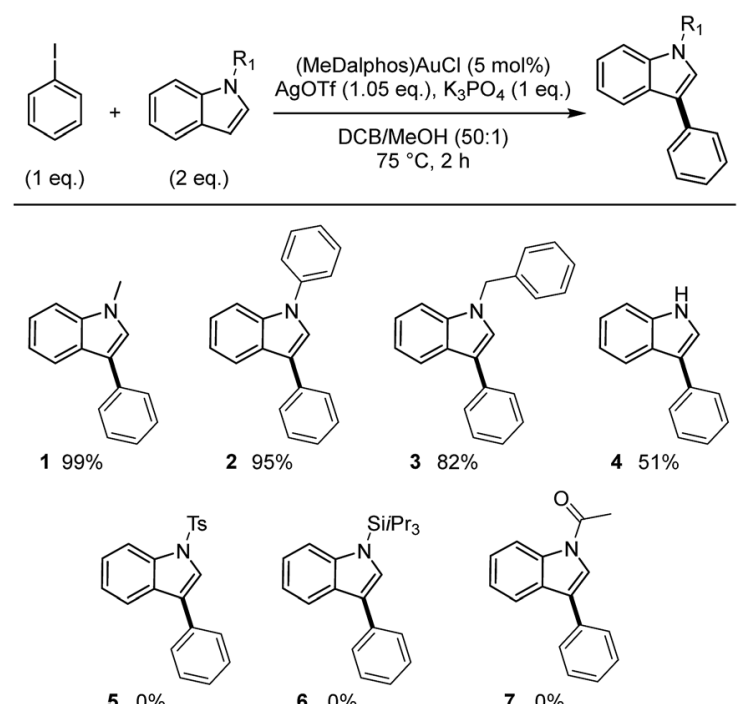

$50 \%$
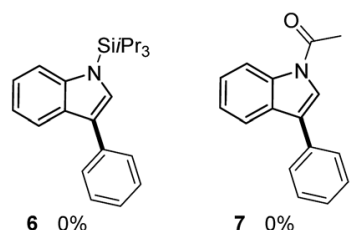

Scheme 4 Scope of $\mathrm{N}$-substituted indoles. Cross-coupling of iodobenzene and indoles catalyzed by the $(P, N)$ gold complex. Yields determined using calibrated GC-MS with $n$-dodecane as internal standard. complementary to those usually observed upon Pd- and $\mathrm{Cu}$ catalyzed arylation of $\mathrm{N}-\mathrm{H}$ indoles. $^{34,35}$ The operating conditions for the $\mathrm{Au}(\mathrm{I}) / \mathrm{Au}(\mathrm{III})$ arylation of indoles are remarkably mild for such reactions $\left(2 \mathrm{~h}\right.$ at $75^{\circ} \mathrm{C}$, while Pd catalysts typically require heating at $120-150{ }^{\circ} \mathrm{C}$ for $\left.\sim 24 \mathrm{~h}\right) .{ }^{27 b}$

The scope of iodoarenes was then examined with $N$-methyl indole as partner (Scheme 5). Pleasingly, the arylation proceeds with good yields and complete $\mathrm{C} 3$ selectivity with both electronrich (8-9) and electron-deficient (10-12) para-substituted iodobenzenes. More sterically hindered substrates such as 1- and 2iodonaphthalenes as well as ortho-methoxy iodobenzene also react smoothly and regioselectively (16-18). Notably, bifunctional iodoarenes featuring $\mathrm{C}-\mathrm{Br}$ or $\mathrm{C}-\mathrm{OTf}$ bonds display complete chemoselectivity. In contrast to $\mathrm{Pd}$-catalysts that usually react with $\mathrm{C}-\mathrm{I}, \mathrm{C}-\mathrm{Br}$ and $\mathrm{C}-\mathrm{OTf}$ bonds with limited selectivity, only the $\mathrm{C}-\mathrm{I}$ bond is activated at gold under these conditions. The corresponding C3-arylated indoles 13 and 14 are obtained in good to excellent yields and offer the possibility for subsequent cross-coupling transformations. Boronate moieties are also compatible with the gold-catalyzed arylation,

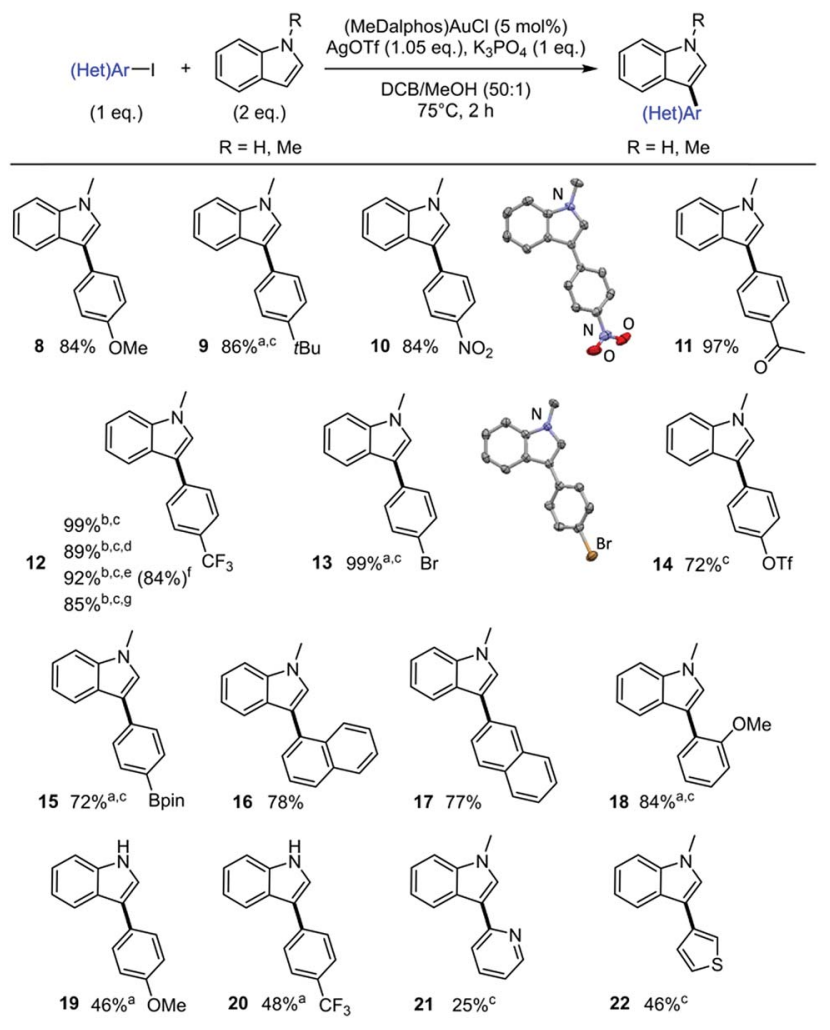

Scheme 5 Scope of iodoarenes. Cross-coupling of iodoarenes and $N$-methyl indole catalyzed by the $(P, N)$ gold complex. Unless otherwise stated, yields determined using calibrated GC-MS with $n$ dodecane as internal standard. Crystallographic structures of indoles 10 and 13 as inserts. Reaction conditions: $0.1 \mathrm{M}$ of aryl iodide. ${ }^{\mathrm{D}} \mathrm{DTBP}$ (2 eq.) instead of $\mathrm{K}_{3} \mathrm{PO}_{4} \cdot{ }^{\mathrm{b}} \mathrm{DTBP}\left(1 \mathrm{eq}\right.$.) and $\mathrm{N}$-methyl indole $\left(1\right.$ eq.). ${ }^{\mathrm{C}}$ Yields determined by NMR with $n$-dodecane as internal standard. ${ }^{d} A l l$ reagents weighted in air. ${ }^{\mathrm{e}} \mathrm{N}$-methyl indole $(1 \mathrm{~g}), 2 \mathrm{~mol} \%$ (MeDalphos) $\mathrm{AuCl}, 4.5 \mathrm{~h}, 1.3 \mathrm{M}$ of aryl iodide. ${ }^{\mathrm{f}}$ Isolated yield in parenthesis. ${ }^{9} \mathrm{~N}-$ methyl indole $(1 \mathrm{~g}), 1 \mathrm{~mol} \%$ (MeDalphos)AuCl, overnight, $1.4 \mathrm{M}$ of aryl iodide. 
as shown by the preparation of compound $15 .{ }^{36}$ The scope of iodoarenes was further studied with $\mathrm{N}-\mathrm{H}$ indole. With both electron-rich (19) and electron-deficient (20) substrates, the arylation proceeds with moderate yield but complete C3 selectivity. Preliminary tests with 2-iodopyridine and 3-iodothiophene show that the reaction is also feasible with heteroaryl iodides (21 and 22), although the corresponding C3-arylated indoles were obtained in moderate yields. Note that in some cases, the use of 2,6-di-tert-butylpyridine (DTBP) instead of $\mathrm{K}_{3} \mathrm{PO}_{4}$ as the base afforded better results (for example indole 9 was obtained in $86 \%$ yield with DTBP but only $37 \%$ with $\mathrm{K}_{3} \mathrm{PO}_{4}$ ). $\mathrm{X}$-ray diffraction analyses of compounds 10 and 13 unambiguously confirmed the regiochemical outcome of the indole arylation. ${ }^{\mathbf{1 4}}$

The robustness and scalability of the reaction was assessed using 4-iodobenzotrifluoride as substrate. The corresponding C3-arylated indole 12 was obtained in excellent yield using only 1 eq. of $N$-methyl indole. The reaction displays low air and moisture sensitivity. It allows the use of commercial chemicals without further purification and does not require inert atmosphere. The synthetic applicability of the process was further substantiated by carrying out gram scale experiments using lower catalytic loadings. The C3-arylated indole 12 was for example obtained in $85 \%$ yield when performing the reaction overnight with 1 mol\% of (MeDalphos)AuCl.

Then the influence of the substitution pattern at the indole moiety was investigated. The coupling of iodobenzene with a variety of $N$-methyl indoles was tested (Scheme 6). No coupling product was obtained from 2-methyl indole, indicating that the reaction is very sensitive to steric hindrance at this position. Conversely, indoles methylated at either C4, C5, C6 or C7 position readily couple with iodobenzene to give the corresponding C3-arylated products 24-27 in good yields. Particularly noteworthy is the 4-methyl substrate in which the proximity of the methyl substituent at $\mathrm{C} 4$ does not hamper the

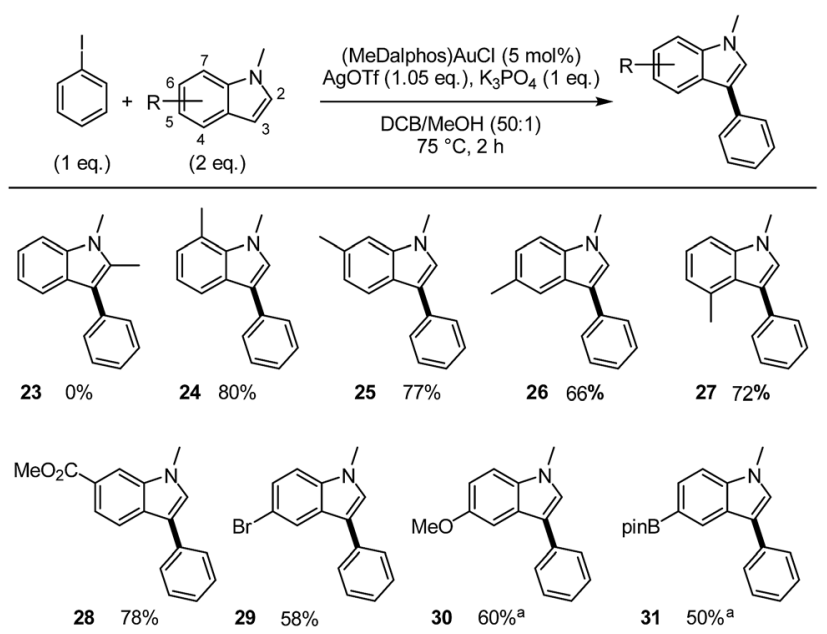

Scheme 6 Scope of substituted $N$-methylindoles. Cross-coupling of iodobenzene and indoles catalyzed by the $(P, N)$ gold complex. Yields determined by ${ }^{1} \mathrm{H}$ NMR with $n$-dodecane as internal standared. ${ }^{\text {a }}$ DTBP (1eq.). arylation in the $\mathrm{C} 3$ position. It is also worth noting that common functional groups are well tolerated on the indole partner, as illustrated by the preparation of the $\mathrm{CO}_{2} \mathrm{Me}, \mathrm{Br}, \mathrm{OMe}$ and Bpin-substituted products 28-31.

A robustness screen was also conducted to further assess the tolerance of the catalytic reaction towards various functional groups. The arylation of $N$-methyl indole with iodobenzene was undertaken in the presence of one molar equivalent of additives. The yield of 1 was determined by GC-MS analysis, as well as the amount of additive and starting material (SM) remaining (see Table S3 in the ESI $\dagger$ ). ${ }^{37}$ The results show that alkenes (1octene), alcohols (phenol, methanol), amides (acetanilide) and nitriles (benzonitrile) are well tolerated: the coupling product 1 is obtained in $>87 \%$ yield, the recovery yields of excess substrate ( $N$-methyl indole) and additive are $>94 \%$ and $>74 \%$, respectively. In contrast, the presence of acids (benzoic acid) or amines ( $p$-toluidine) completely quenched the reactivity, while the addition of aldehydes (cyclohexanecarboxaldehyde) or ketones (cyclohexanone) gives rise to side-reactions with consumption of both the $\mathrm{N}$-methyl indole and the additive. Compatibility of heterocycles was also studied. While imidazole inhibited the reaction, the presence of thiophene and benzofurane did not alter the catalytic arylation of the indole.

\section{Conclusions}

Judicious choice of ligand has been recently demonstrated to emulate oxidative addition of iodo- and bromoarenes to gold, a basic elementary step long considered inadequate to access aryl gold(III) complexes. Among the three sets of suitable ligands, only the hemilabile (P,N) MeDalphos ligand has been shown to date to pave the way for $\mathrm{Au}(\mathrm{I}) / \mathrm{Au}(\mathrm{III})$ catalysis from aryl halides. The present study advances our knowledge of the factors controlling this new gold reactivity and its synthetic interest is illustrated in an important catalytic transformation, namely the $\mathrm{C} 3$ arylation of indoles.

In the presence of $\mathrm{AgSbF}_{6}$, the (MeDalphos)AuCl complex reacts instantaneously and quantitatively with a variety of iodoarenes at room temperature. To assess the influence of electronics on the oxidative addition, competition experiments have been performed with para-substituted substrates, revealing a clear preference for electron-rich iodoarenes. Thus, whatever the ligand, $(\mathrm{P}, \mathrm{P}),(\mathrm{N}, \mathrm{N})$ or $(\mathrm{P}, \mathrm{N})$, gold displays in oxidative addition a reactivity trend opposite to that typically encountered with palladium. Of note, similar competition experiments could be carried out with the (P,N) ligand under catalytic conditions. The cross-coupling of 1,3,5-trimethoxybenzene with para-substituted iodoarenes was found to follow the same trend, showing that the unique preference of gold for electron-rich substrates can be transposed from the elementary step to a catalytic transformation.

Analysis of the oxidative addition process by DFT calculations has provided a plausible rationale for the different behavior of gold and palladium. Indeed, the respective transition states display opposite electron flows according to NBO, CDA and ETS-NOCV analyses. Despite the donor bidentate ligand, the cationic $\left(\mathrm{L}, \mathrm{L}^{\prime}\right) \mathrm{Au}^{+}$complexes are highly electrophilic 
and significant $\mathrm{PhI} \rightarrow$ Au charge transfer is observed at the oxidative addition transition state. Conversely, metal to PhI back-donation is prevalent for neutral $\mathrm{L}_{2} \mathrm{Pd}(0)$ complexes, which explains why electron-deprived substrates are more reactive.

Taking advantage of the facile oxidative addition of iodoarenes and of the propensity of the ensuing aryl gold(III) complexes to react with electron-rich (hetero)arenes via electrophilic $\mathrm{C}-\mathrm{H}$ activation, we have applied the (MeDalphos)AuCl complex to the catalytic arylation of indoles. The transformation proved to be very efficient, general and robust. As the recently developed gold-catalyzed oxidative arylation of indoles, it displays complete regioselectivity for $\mathrm{C} 3$ arylation and thus nicely complements the Pd-catalyzed transformations that tend to favor C2 arylation. The (MeDalphos)AuCl complex operates under mild conditions $\left(75^{\circ} \mathrm{C}, 2 \mathrm{~h}\right)$ without any external oxidant. As a result, it does not require protection of the $\mathrm{N}$ atom of the indole and tolerates a variety of functional groups at both the iodoarene and indole partners $\left(\mathrm{NO}_{2}, \mathrm{CO}_{2} \mathrm{Me}, \mathrm{Br}\right.$, OTf, Bpin, OMe...).

This study underscores the unique properties of $(\mathrm{P}, \mathrm{N})$ gold complexes towards oxidative addition and highlights their potential in $\mathrm{Au}(\mathrm{I}) / \mathrm{Au}(\mathrm{III})$ catalysis with aryl halide electrophiles. Future studies will aim to further develop this chemistry by taking advantage of the easy access and rich reactivity of aryl gold(III) complexes.

\section{Conflicts of interest}

There are no conflicts to declare.

\section{Acknowledgements}

Financial support from the Centre National de la Recherche Scientifique and the Université de Toulouse is gratefully acknowledged. J. R. thanks the Fundación Ramón Areces for a post-doctoral fellowship and the European Commission for a MCIF (Gold3Cat-799606). The "Direction du Numérique" of the Université de Pau et des Pays de l'Adour, MCIA (Mésocentre de Calcul Intensif Aquitain) and CINES under allocation A005080045 made by Grand Equipement National de Calcul Intensif (GENCI) are acknowledged for computational facilities. E. D. Sosa Carrizo thanks CDAPP for funding part of his postdoctoral contract.

\section{Notes and references}

1 (a) D. J. Gorin and F. D. Toste, Nature, 2007, 446, 395-403; (b) T. Lauterbach, M. Livendahl, A. Rosellón, P. Espinet and A. M. Echavarren, Org. Lett., 2010, 12, 3006-3009; (c) M. Livendahl, P. Espinet and A. M. Echavarren, Platinum Met. Rev., 2011, 55, 212-214; (d) A. S. K. Hashmi, C. Lothschütz, R. Döpp, M. Ackermann, J. De Buck Becker, M. Rudolph, C. Scholz and F. Rominger, Adv. Synth. Catal., 2012, 354, 133-147; (e) M. Livendahl, C. Goehry, F. Maseras and A. M. Echavarren, Chem. Commun., 2014, 50, 1533-1536.
2 For reviews on gold-catalyzed oxidative couplings, see: $(a)$ P. Garcia, M. Malacria, C. Aubert, V. Gandon and L. Fensterbank, ChemCatChem, 2010, 2, 493-497; (b) M. N. Hopkinson, A. D. Gee and V. Gouverneur, Chem.Eur. J., 2011, 17, 8248-8262; (c) H. A. Wegner and M. Auzias, Angew. Chem., Int. Ed., 2011, 50, 8236-8247; (d) T. C. Boorman and I. Larrosa, Chem. Soc. Rev., 2011, 40, 1910-1925. For reviews dealing with oxidant-free goldcatalysis and dual photoredox/gold catalysis, see: $(e)$ M. N. Hopkinson, A. Tlahuext-Aca and F. Glorius, Acc. Chem. Res., 2016, 49, 2261-2272; (f) M. O. Akram, S. Banerjee, S. S. Saswade, V. Bedi and N. T. Patil, Chem. Commun., 2018, 54, 11069-11083; $(g)$ M. Zidan, S. Rohe, T. McCalluma and L. Barriault, Catal. Sci. Technol., 2018, 8, 6019-6028; (h) C.-S. Wang, P. H. Dixneuf and J.-F. Soulé, Chem. Rev., 2018, 118, 7532-7585.

3 For selected references, see: $(a)$ L. T. Ball, G. C. Lloyd-Jones and C. A. Russell, Science, 2012, 337, 1644-1648; (b) L. T. Ball, G. C. Lloyd-Jones and C. A. Russell, J. Am. Chem. Soc., 2014, 136, 254-264; (c) T. J. A. Corrie, L. T. Ball, C. A. Russell and G. C. Lloyd-Jones, J. Am. Chem. Soc., 2017, 139, 245-254; (d) M. P. Robinson and G. C. Lloyd-Jones, ACS Catal., 2018, 8, 7484-7488; (e) X. C. Cambeiro, N. Ahlsten and I. Larrosa, J. Am. Chem. Soc., 2015, 137, 15636-15639; (f) Q. Wu, C. Du, Y. Huang, X. Liu, Z. Long, F. Song and J. You, Chem. Sci., 2015, 6, 288-293; (g) Y. Hua, P. Asgari, T. Avullala and J. Jeon, J. Am. Chem. Soc., 2016, 138, 7982-7991; $(h)$ M. Hofer, A. Genoux, R. Kumar and C. Nevado, Angew. Chem., Int. Ed., 2017, 56, 1021-1025; (i) W. Li, D. Yuan, G. Wang, Y. Zhao, J. Xie, S. Li and C. Zhu, J. Am. Chem. Soc., 2019, 141, 3187-3197.

4 For selected references, see: (a) L. T. Ball, M. Green, G. C. Lloyd-Jones and C. A. Russell, Org. Lett., 2010, 12, 4724-4727; (b) L. T. Ball, G. C. Lloyd-Jones and C. A. Russell, Chem.-Eur. J., 2012, 18, 2931-2937; (c) M. J. Harper, E. J. Emmett, J. F. Bower and C. A. Russell, J. Am. Chem. Soc., 2017, 139, 12386-12389; (d) A. D. Melhado, W. E. Brenzovich, A. D. Lackner and F. D. Toste, J. Am. Chem. Soc., 2010, 132, 8885-8887; (e) W. E. Brenzovich, D. Benitez, A. D. Lackner, H. P. Shunatona, E. Tkatchouk, W. A. Goddard and F. D. Toste, Angew. Chem., Int. Ed., 2010, 49, 5519-5522; (f) G. Zhang, L. Cui, Y. Wang and L. Zhang, J. Am. Chem. Soc., 2010, 132, 1474-1475.

5 For selected references, see: $(a)$ B. Sahoo, M. N. Hopkinson and F. Glorius, J. Am. Chem. Soc., 2013, 135, 5505-5508; (b) M. N. Hopkinson, B. Sahoo and F. Glorius, Adv. Synth. Catal., 2014, 356, 2794-2800; (c) S. Kim, J. Rojas-Martin and F. D. Toste, Chem. Sci., 2016, 7, 85-88; (d) V. Gauchot and A.-L. Lee, Chem. Commun., 2016, 52, 10163-10166; (e) V. Gauchot, D. R. Sutherland and A.-L. Lee, Chem. Sci., 2017, 8, 2885-2889; (f) B. Dong, H. Peng, S. E. Motika and X. Shi, Chem.-Eur. J., 2017, 23, 11093-11099; (g) J. Xie, K. Sekine, S. Witzel, P. Krämer, M. Rudolph, F. Rominger and A. S. K. Hashmi, Angew. Chem., Int. Ed., 2018, 57, 16648-16653; (h) S. Witzel, K. Sekine, M. Rudolph and A. S. K. Hashmi, Chem. Commun., 2018, 54, 13802-13804. 
6 (a) M. Joost, A. Zeineddine, L. Estévez, S. Mallet-Ladeira, K. Miqueu, A. Amgoune and D. Bourissou, J. Am. Chem. Soc., 2014, 136, 14654-14657; (b) A. Zeineddine, L. Estévez, S. Mallet-Ladeira, K. Miqueu, A. Amgoune and D. Bourissou, Nat. Commun., 2017, 8, 565-572; (c) M. J. Harper, C. J. Arthur, J. Crosby, E. J. Emmett, R. L. Falconer, A. J. Fensham-Smith, P. J. Gates, T. Leman, J. E. McGrady, J. F. Bower and C. A. Russell, J. Am. Chem. Soc., 2018, 140, 4440-4445.

7 For oxidant-free gold-catalyzed halogen exchange, $\mathrm{C}-\mathrm{N}$ and $\mathrm{C}-\mathrm{O}$ coupling with chelating aryl halides, see: (a) J. Serra, C. J. Whiteoak, F. Acuna-Pares, M. Font, J. M. Luis, J. Lloret-Fillol and X. Ribas, J. Am. Chem. Soc., 2015, 137, 13389-13397; (b) J. Serra, T. Parella and X. Ribas, Chem. Sci., 2017, 8, 946-952.

8 Some aryl gold(III) species deriving from aryl diazonium salts have also been isolated thanks to the use of ancillary chelating ligands, see: (a) A. Tlahuext-Aca, M. N. Hopkinson, C. G. Daniliuc and F. Glorius, Chem.Eur. J., 2016, 22, 11587-11592; (b) L. Huang, F. Rominger, M. Rudolph and A. S. K. Hashmi, Chem. Commun., 2016, 52, 6435-6438; (c) E. O. Asomoza-Solís, J. Rojas-Ocampo, R. A. Toscano and S. Porcel, Chem. Commun., 2016, 52, 7295-7298; (d) A. Tabey, M. Berlande, P. Hermange and E. Fouquet, Chem. Commun., 2018, 54, 12867-12870.

9 (a) M. Joost, L. Estévez, K. Miqueu, A. Amgoune and D. Bourissou, Angew. Chem., Int. Ed., 2015, 54, 5236-5240; (b) J. H. Teles, Angew. Chem., Int. Ed., 2015, 54, 5556-5558.

10 Little is known yet about the effects of aryl electronics in $\mathrm{Au}(\mathrm{III})$ and $\mathrm{Au}(\mathrm{I}) / \mathrm{Au}(\mathrm{III})$ reactivity. See: (a) ref. 3b; (b) K. Kang, S. Liu, T. Xu, D. Wang, X. Leng, R. Bai, Y. Lan and Q. C. Shen, Organometallics, 2017, 36, 4727-4740; (c) L. Rocchigiani, J. Fernandez-Cestau, P. H. M. Budzelaar and M. Bochmann, Chem.-Eur. J., 2018, 24, 8893-8903.

11 (a) J. F. Hartwig, Organotransition Metal Chemistry: From Bonding to Catalysis, Universtity science books ed., Sausalito, CA, 2009; (b) K. C. Lam, T. B. Marder and Z. Lin, Organometallics, 2007, 26, 758-760.

12 R. J. Lundgren, K. D. Hesp and M. Stradiotto, Synlett, 2012, 17, 2443-2458.

13 M. S. Messina, J. M. Stauber, M. A. Waddington, A. L. Rheingold, H. D. Maynard and A. M. Spokoyny, J. Am. Chem. Soc., 2018, 140, 7065-7069.

14 See ESI. $\dagger$

15 H. Hansch, A. Leo and R. W. Taft, Chem. Rev., 1991, 91, 165195.

16 (a) C. Amatore and F. Pflüger, Organometallics, 1990, 9, 22762282; (b) L. A. Perego, P.-A. Payard, B. Haddou, I. Ciofini and L. Grimaud, Chem.-Eur. J., 2018, 24, 2192-2199.

17 Same calculations have been performed on the $(\mathrm{N}, \mathrm{N})$ and $(\mathrm{P}, \mathrm{P})$ chelated gold complexes $^{6 \mathrm{a}, \mathrm{c}}$ which displayed preference for electron-rich aryl iodides. Similar results were obtained with electron transfer from iodobenzene to the (L,L)Au+ fragment at the transition state of oxidative addition, and prevalent substrate to metal donation. ${ }^{14}$.

18 (a) D. Sorbelli, L. Belpassi, F. Tarantelli and P. Belanzoni, Inorg. Chem., 2018, 57, 6161-6175; (b) C. A. Gaggioli,
L. Belpassi, F. Tarantelli and P. Belanzoni, Chem. Commun., 2017, 53, 1603-1606; (c) G. Bistoni, S. Rampino, N. Scafuri, G. Ciancaleoni, D. Zuccaccia, L. Belpassi and F. Tarantelli, Chem. Sci., 2016, 7, 1174-1184.

19 (a) H. M. Senn and T. Ziegler, Organometallics, 2004, 23, 2980-2988; (b) M. Ahlquist, P. Fristrup, D. Tanner and P.-O. Norrby, Organometallics, 2006, 25, 2066-2073; (c) See also ref. $11 \mathrm{~b}$.

20 (a) M. Joost, L. Estevez, S. Mallet-Ladeira, K. Miqueu, A. Amgoune and D. Bourissou, Angew. Chem., Int. Ed., 2014, 53, 14512-14516; (b) A. Zeineddine, F. Rekhroukh, E. D. Sosa Carrizo, S. Mallet-Ladeira, K. Miqueu, A. Amgoune and D. Bourissou, Angew. Chem., Int. Ed., 2018, 57, 1306-1310.

21 For recent computational studies of gold complexes using the ETS-NOCV approach, see: (a) P. Jerabek, H. W. Roesky, G. Bertrand and G. Frenking, J. Am. Chem. Soc., 2014, 136, 17123-17135; (b) E. P. A. Couzijn, Y.-Y. Lai, A. Limacher and P. Chen, Organometallics, 2017, 36, 3205-3214; (c) R. Bhattacharjee and A. Datta, Chem.-Eur. J., 2018, 24, 13636-13646; (d) A. Couce-Rios, A. Lledós, I. Fernández and G. Ujaque, ACS Catal., 2019, 9, 848-858.

$22 \rho$ values from 0.29 to 1.44 have been reported for Pdcatalyzed cross-couplings of para-substituted iodoarenes: (a) C. Consorti, G. Ebeling, F. Flores, F. Rominger and J. Dupont, Adv. Synth. Catal., 2004, 346, 617-624; (b) D. Zim, S. M. Nobre and A. L. Monteiro, J. Mol. Catal. A: Chem., 2008, 287, 16-23; (c) D. E. Stephens, J. Lakey-Beitia, A. C. Atesin, T. A. Ateşin, G. Chavez, H. D. Arman and O. V. Larionov, ACS Catal., 2015, 5, 167-175.

23 A small negative $\rho$ value $(-0.25)$ was reported for the Ullmann Cu-catalyzed coupling of iodoarenes with diarylamines: A. J. Paine, J. Am. Chem. Soc., 1987, 109, 1496-1502.

24 N. Chadha and O. Silakari, Eur. J. Med. Chem., 2017, 134, 159-184.

25 (a) E. M. Beck and M. J. Gaunt, Top. Curr. Chem., 2010, 292, 85-121; (b) N. Lebrasseur and I. Larrosa, in Advances in Heterocyclic Chemistry, ed. A. Katritzky, Academic Press, USA, 2012, vol. 105, pp. 309-351; (c) A. H. Sandtorv, Adv. Synth. Catal., 2015, 357, 2403-2435; (d) L. Ping, D. S. Chung, J. Bouffard and S. G. Lee, Chem. Soc. Rev., 2017, 46, 4299-4328.

26 For transition-metal-free processes using highly electrophilic arylating substrates (i.e. diazonium salts) or highly reactive metalating reagents (such as potassium tertbutylate or lithium tetramethylpiperidine), see: (a) L. Ackermann, M. Dell'Acqua, S. Fenner, R. Vicente and R. Sandmann, Org. Lett., 2011, 13, 2358-2360; (b) Y.-P. Zhang, X.-L. Feng, Y.-S. Yang and B.-X. Cao, Tetrahedron Lett., 2016, 57, 2298-2302; (c) T. Truong and O. Daugulis, J. Am. Chem. Soc., 2011, 133, 4243-4245; (d) J. Chen and J. Wu, Angew. Chem., Int. Ed., 2017, 56, 39513955.

27 (a) X. Wang, B. S. Lane and D. Sames, J. Am. Chem. Soc., 2005, 127, 4996-4997; (b) X. Wang, D. V. Gribkov and D. Sames, J. Org. Chem., 2007, 72, 1476-1479; (c) N. R. Deprez, D. Kalyani, 
A. Krause and M. S. Sanford, J. Am. Chem. Soc., 2006, 128, 4972-4973; (d) H. P. L. Gemoets, I. Kalvet, A. V. Nyuchev, N. Erdmann, V. Hessel, F. Schoenebeck and T. Noel, Chem. Sci., 2017, 8, 1046-1055; (e) C. Sollert, K. Devaraj, A. Orthaber, P. J. Gates and L. T. Pilarski, Chem.-Eur. J., 2015, 21, 5380-5386.

28 (a) B. S. Lane, M. A. Brown and D. Sames, J. Am. Chem. Soc., 2005, 127, 8050-8057; (b) D. R Stuart and K. Fagnou, Science, 2007, 316, 1172-1175; (c) R. J. Phipps, N. P. Grimster and M. J. Gaunt, J. Am. Chem. Soc., 2008, 130, 8172-8174; (d) B. Join, T. Yamamoto and K. Itami, Angew. Chem., Int. Ed., 2009, 48, 3644-3647; (e) K. Yamaguchi, H. Kondo, J. Yamaguchi and K. Itami, Chem. Sci., 2013, 4, 3753-3757; (f) S. Perato, B. Large, Q. Lu, A. Gaucher and D. Prim, ChemCatChem, 2017, 9, 389-392.

29 For examples of indole arylation at remote positions, see: $(a)$ Y. Yang and Z. Shi, Chem. Commun., 2018, 54, 1676-1685; (b) J. Kalepu, P. Gandeepan, L. Ackermann and L. T. Pilarski, Chem. Sci., 2018, 9, 4203-4216; (c) X. Qiu, H. Deng, Y. Zhao and Z. Shi, Sci. Adv., 2018, 4, eaau6468; (d) X. Qiu, P. Wang, D. Wang, M. Wang, Y. Yuan and Z. Shi, Angew. Chem., Int. Ed., 2019, 58, 1504-1508 and references cited therein.

30 (a) K. Hata, H. Ito, Y. Segawa and K. Itami, Beilstein J. Org. Chem., 2015, 11, 2737-2746; (b) A. J. Cresswell and G. C. Lloyd-Jones, Chem.-Eur. J., 2016, 22, 12641-12645.
31 The catalytic reaction did not proceed when the $\mathrm{K}_{3} \mathrm{PO}_{4} /$ AgOTf combination was replaced by $\mathrm{Ag}_{3} \mathrm{PO}_{4}$.

32 Y. Zou, G. Yue, J. Xu and J. Zhou, Eur. J. Org. Chem., 2014, 5901-5905.

33 Electrophilic substitutions are known to proceed selectively at the C3 position of indoles: A. H. Jackson and P. P. Lynch, J. Chem. Soc., Perkin Trans. 2, 1987, 1215-1219.

34 Pd catalysts generally show high C2 selectivity (see ref. 25). For a rare example of $\mathrm{C} 3$ arylation of $\mathrm{N}-\mathrm{H}$ indoles, using sterically demanding magnesium salts, see ref. 28a.

$35 \mathrm{Cu}$ catalysts generally promote $N$-arylation, see: (a) L. Hu, P. Guo, G. Li, J. Lan, R. Xie and J. You, J. Org. Chem., 2007, 72, 8535-8538; (b) S. Xu, X. Huang, X. Hong and B. Xu, Org. Lett., 2012, 14, 4614-4617; (c) C3-regioselective arylation of $\mathrm{N}-\mathrm{H}$ indoles has been observed using diaryl iodonium salts and $\mathrm{Cu}(\mathrm{OTf})_{2}$ as catalyst, see ref. $28 \mathrm{c}$.

36 For the selective coupling of B,Si-difunctional arenes with aryl diazonium salts with gold catalysts under irradiation, see ref. $5 \mathrm{~g}$.

37 For recent discussions of such robustness screening, see: $(a)$ K. D. Collins and F. Glorius, Nat. Chem., 2013, 5, 597-601; (b) K. D. Collins and F. Glorius, Acc. Chem. Res., 2015, 48, 619627; (c) T. Gensch and F. Glorius, Science, 2016, 352, 294295; (d) L. Pitzer, F. Schäfers and F. Glorius, Angew. Chem., Int. Ed., 2019, 58, 8572-8576. 